\title{
Práticas corporais e artísticas, aprendizagem inventiva e cuidado de si $^{\star}$
}

\author{
Flavia Liberman, ${ }^{I, \star}$ Elizabeth Maria Freire de Araújo Lima, ${ }^{I I}$ \\ Viviane Santalucia Maximino, I Yara Maria de Carvalho ${ }^{I I}$ \\ ${ }^{I}$ Universidade Federal de São Paulo, Santos, SP, Brasil

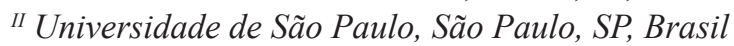

\begin{abstract}
Resumo
Nos últimos anos temos trabalhado com as práticas corporais e artísticas na formação, e junto a comunidades, em serviços de saúde e espaços de produção artística, entendendo que essas práticas promovem a produção de cuidado, o encontro e o aumento de potência de vida, segundo uma ética que resiste aos modelos prescritivos, normativos e excludentes, incidindo nos processos de subjetivação. Aqui apresentamos experimentações com o corpo, que envolvem a dança, a música, as artes e a escrita, e discutimos as relações entre Aprendizagem Inventiva, experiência estética e o cuidado de si, tomados como referências conceituais para pensar os corpos em estado de presença, produzindo conexões, inventividade e um voltar-se para si com implicações coletivas, politicas, clínicas e estéticas que movimentam o pensamento, os corpos e a vida.
\end{abstract}

Palavras-chave: práticas corporais; formação em saúde; cuidado de si; aprendizagem inventiva; experiência estética.

\section{Corporal and artistic practices, inventive learning and the care of the self}

\begin{abstract}
In the last years we have worked with corporal and artistic practices with students and communities, in institutions of health and spaces of artistic production, understanding that these practices promote the production of care, the encounter and the increase of the potency of life, according to an ethics which resists prescriptive, normative and exclusive models, focusing on the processes of subjectivation. Here we present experimentations with the body - involving dance, music, arts and writing - and discuss the relationships between Inventive Learning, aesthetic experience and the care of the self, taken as conceptual references to think bodies in a state of presence, producing connections, inventiveness and a turning to oneself with collective, political, clinical and aesthetic implications that move thought, bodies and life.
\end{abstract}

Keywords: corporal practices; professional education in health; care of the self; inventive learning; aesthetic experience.

\section{Introdução}

Como fazer com que a música, a dança, a criação, todas as formas de sensibilidade, pertençam de pleno direito ao conjunto dos componentes sociais? [...] Como produzir novos agenciamentos de singularização que trabalhem por uma sensibilidade estética, pela mudança da vida num plano mais cotidiano e, ao mesmo tempo, pelas transformações sociais a nível dos grandes conjuntos econômicos e sociais? (GUATTARI; ROLNIK, 1986, p. 22).

Este texto apresenta experimentações com práticas corporais e estéticas em contextos de formação e produção artística. Para expor essas práticas transformamos em narrativas o que nos aconteceu e assim oferecemos matéria prima para as discussões que buscam correlacionar esses temas aos processos formativos em saúde, à Aprendizagem Inventiva e ao cuidado de si.

Em diferentes contextos e cenários - estéticos, de formação e de intervenção, buscamos migrar do lugar daqueles que possuem o saber e "tratam as pessoas" prescritivamente, para um outro lugar...um lugar de produção de conversa, escuta e fazer junto que nos ensina sobre os desequilíbrios, os riscos, as incertezas, os desconfortos, como espaços e afetos potentes para ressignificar as relações consigo mesmo e com os outros.

\footnotetext{
^Financiamento próprio.

$\star \star$ Endereço para correspondência: Universidade Federal de São Paulo- Baixada Santista. Av. Dona Ana Costa, 95. Vl. Mathias - Santos, SP - Brasil. CEP 11060-001.E-mail: toflavia.liberman@gmail.com, beth.lima@usp.br, vivimax9@gmail.com, yaramc@usp.br
}

Para dar passagem a essas dinâmicas, cultivamos e compartilhamos patrimônios da humanidade: os cantos, as escritas, as danças, as leituras, as performances entre outras artes, como modos distintos de movimento, a fim de reconhecer e brincar com os fluxos e ritmos da vida.

Temos conduzido práticas corporais e artísticas que colocam em suspensão modos estratificados de pensar e agir com os corpos, acompanhando o impacto dessas iniciativas que reverberam em várias direções. Os encontros entre corpos (LIBERMAN, 2008) nos movimentam e nos incitam ao trabalho expressivo, abrindo diferentes canais perceptivos que ampliam nossas sensibilidades, lugares e tempos. Nossos coletivos têm, cada vez mais, apostado nas trocas, nas forças do agir e do pensar, que implicam no Cuidado de si (FOUCAULT, 2006).

Como balizadora para essas intervenções trabalhamos com o método da cartografia (PASSOS; KASTRUP; ESCOSSIA, 2010) que serve como guia para delinear trajetos, considerando a existência de inúmeras camadas, micro e macropolíticas, para a compreensão daquilo que fazemos com os corpos. Reconhecendo e acolhendo a imprevisibilidade, as incertezas e o desejo de persistir nesse caminho investimos em uma ética afirmativa na produção de bons e alegres encontros (SPINOZA, 2007). Nossos caminhos são traçados no próprio caminhar, realizados em redes conectivas que se (re)configuram permanentemente nos encontros e nas composições, ou não, entre os corpos, sejam eles pessoas, objetos, cheiros, ondas ou ventos. 
Especialmente nos cenários de formação, considerando sua dimensão coletiva, provocamos $\mathrm{e}$ ampliamos nossos olhares para os acontecimentos e problematizamos distintas questões: a relação saúde e arte; a importância das práticas corporais e artísticas como práticas de cuidado de si; a potência destas na atuação profissional, em diferentes contextos, no trabalho interprofissional e na atuação em grupos e com grupos.

Pautamo-nos pelo conceito de Aprendizagem Inventiva (KASTRUP, 2010), para a produção de conhecimento corporificado (KELEMAN, 1992), que cria marcas (ROLNIK, 1993) ampliando repertórios existenciais. Trata-se de um convite permanentemente à experimentação de processos vivos, fluidos e, sobretudo, movimentos pensantes. A formação, assim, diz dos processos de subjetivação que decorrem das experiências complexas que agregam a dimensão dos afetos e das sensibilidades. Os tempos de formação e intervenção, de aprendizagem e invenção coexistem e colocam em cena todos os corpos e, particularmente, o corpo em estado de presença, pressupondo uma ética do saber implicado, uma ética do Cuidado de si (FOUCAULT, 2006).

\section{Aprendizagem Inventiva, experiência estética e cuidado de si}

Kastrup chama de Aprendizagem Inventiva o desencadeamento de um processo de criação, que pode ocorrer quando nos encontramos com algo que nos surpreende, provocando estranhamento e nos forçando a pensar. (KASTRUP, 2010). A Aprendizagem Inventiva (KASTRUP, 2004, 2005, 2007, 2010) colocase como uma política cognitiva na qual o sujeito é instigado a criar situações e pensamentos ao invés de apresentar respostas a problemas já existentes. Difere da aprendizagem que vê a cognição (percepção, memória, linguagem e solução de problemas) apenas como aparato para o processamento de informação, deixando de lado aspectos afetivos, emocionais, sociais, políticos, etc., retirando seu caráter de experiência e não abrindo espaço para o questionamento nem para o exercício de um pensamento-imaginação. Este tipo de aprendizagem reforça processos recognitivos e é importante diferenciála da experiência de problematização. A recognição permite o reconhecimento, caracterizando-se pela assimilação do conhecimento anterior e sua utilidade na vida prática. Já a experiência da problematização é aquela que acontece quando os esquemas da recognição são inadequados ou impotentes para assimilar o que se nos apresenta, trazendo um intuito cognitivo, pois pode produzir deslocamentos, suspendendo atitudes naturais e produzindo um processo de Aprendizagem Inventiva (SANCOVSCHI; KASTRUP, 2013).

Deleuze (1988, p. 221- 222) refere-se ao modelo da recognição como um dos modos de funcionamento do pensamento:

A recognição se define pelo exercício concordante de todas as faculdades sobre um objeto suposto como sendo o mesmo: é o mesmo objeto que pode ser visto, tocado, lembrado, imaginado, concebido [...] Mas um objeto é reconhecido quando uma faculdade o visa como idêntico ao de uma outra ou, antes, quando todas as faculdades em conjunto referem seu dado e referem a si mesmas a uma forma de identidade do objeto.

Para este autor, o aprender acontece no choque entre os signos do mundo, na interpretação e produção destes signos que não correspondem fielmente aos seus objetos emissores. Há, portanto, duas facetas: aquela reconhecível e assimilável pela recognição e aquela onde há uma brecha entre o signo e a realidade do seu suporte. É esta faceta inassimilável que, com sua estranheza, causa uma disruptura possibilitando o aprendizado. A ênfase está na relação, não só entre sujeitos, mas também entre estes e o mundo e seus signos. (PASCUAL, JUSTA, 2009). A importância da exterioridade da relação de aprendizagem traz a possibilidade de agenciamentos e ultrapassa o processo exclusivamente subjetivo quando se considera que a invenção é sua matéria-prima.

Para Rolnik, a experiência de desestabilização, que gera inquietação, é inevitável pois resulta da própria demanda da vida, como força que produz efeitos nos corpos. Nesta situação, o desejo é sempre ativado na busca de recobrar o equilíbrio vital, no entanto, de acordo com as políticas predominantes, o modo de resposta à desestabilização pode gerar diferentes efeitos na realidade.

Para que a subjetividade possa sustentar-se na tensão de sua desestabilização entre as formas que produzem certa estabilidade e as forças que a atravessa, é preciso a emergência de um processo de criação que converta as afetações em imagens, palavras, gestos, modos de existência. No entanto, "quando o desejo é capturado pelo mercado e para a produção de capital, pode ser desviado de seu destino criador e o corpo é anestesiado em sua potência de [...] decifrar o mundo a partir de sua condição de vivente: o saber do corpo torna-se inacessível" (ROLNIK, 2015, p. 15).

Vemos, portanto, a importância dos processos criativos na produção de uma subjetividade não submissa e que dê sustentação às desestabilizações próprias da vida. As práticas corporais e artísticas, mobilizando espaços de arte na vida, na formação inventiva e nas ações de cuidado convidam a estes processos.

O conceito de experiência estética de Dewey também nos ajuda a pensar o lugar da arte na Aprendizagem Inventiva. Associando os processos artísticos a situações cotidianas, Dewey traz a concepção de arte como experiência e afirma que, embora muito do que é vivido no cotidiano possa ser perdido, quando a experiência não é interrompida, um fluxo de pensamentos e sensações conduz a pessoa a um estado distinto do estado anterior, fazendo com que esta seja uma experiência estética, marcada por emoções e sensações intensas, que não se dissipam e não são facilmente esquecidas (DEWEY, 2010). A experiência faz aparecer uma nova configuração que é produção de território existencial com as matérias do mundo, gerando processos formativos. 
As experiências estéticas e os processos de criação são próprios da vida e dos corpos e podem acontecer nas situações cotidianas, mas nosso modo de existência produz distâncias entre o corpo e o que ele pode, sua potência e seus processos. O contato com as práticas artísticas e corporais recoloca o problema da aprendizagem sob a perspectiva da invenção:

[...] a arte não é um alvo, mas um atrator caótico, um ponto que é tendencial, sem ser fixo e sem possibilitar falar em regimes estáveis ou em resultados previsíveis. Colocar o problema da aprendizagem do ponto de vista da arte é colocá-lo do ponto de vista da invenção. A arte surge como um modo de exposição do problema do aprender (KASTRUP, 2001, p. 20).

Aprender, portanto, é entrar em processo de transformação acompanhado, comprometido e implicado. Só posso conhecer aquilo que me afeta e com o que me relaciono. Aprender envolve a abertura às experiências estéticas e também às práticas de si. Tomar a própria vida como algo a ser criado. Dobrar a força que incide sobre cada um produzindo sujeitos, para que seja possível viver, sentir e pensar de outra maneira.

$\mathrm{Na}$ Aprendizagem Inventiva, a invenção não é vista como algo raro e excepcional, privilégio exclusivo de artistas ou cientistas, está em nosso cotidiano e permeia o funcionamento cognitivo de todos nós.

Para Foucault (2006), os sujeitos não são uma substância mas formas produzida por jogos de poder e saber e se encontram em relações de produção e de significação que são complexas. Pesquisando as relações entre sujeito e verdade, o autor explorou as práticas do sujeito consigo mesmo, o cuidado de si e sua emergência no mundo grego. Trata-se de práticas e ações pelas quais o sujeito, ele mesmo, se coloca em movimento, atuando daquilo que constitui os modos de subjetivação. Segundo Deleuze (2000, p. 123), Foucault estava se perguntando sobre a possibilidade da resistência: "transpor a linha de força, ultrapassar o poder, [...] seria como curvar a força, fazer com que ela mesma se afete, em vez de afetar outras forças: uma 'dobra', uma relação de força consigo".

$\mathrm{O}$ cuidado de si remete ao conhecer em sentido ampliado como movimento da existência, já que não há acesso ao conhecimento sem uma transformação contínua de si mesmo.

O cuidado de si é certamente o conhecimento de si [...], mas é também o conhecimento de um certo número de regras de conduta ou de princípios que são simultaneamente verdades e prescrições. Cuidar de si é se munir dessas verdades: nesse caso a ética se liga ao jogo da verdade (FOUCAULT, 2004, p. 269).

Por outro lado, o cuidado de si é inseparável de uma atitude diante do outro e implica relações complexas, assim como o sujeito só pode conhecer a si mesmo perante outro sujeito. "Tem-se aí um dos pontos mais importantes dessa atividade consagrada a si mesmo: ela não constitui um exercício da solidão, mas sim uma verdadeira prática social" (FOUCAULT, 1985, p. 57), já que para os gregos, "aquele que cuidasse adequadamente de si era, por isso mesmo, capaz de se conduzir adequadamente em relação aos outros e para os outros" (FOUCAULT, 2004, p. 271).

Assim, o cuidado de si torna-se ponto de referência de uma estética da existência, constituição de um modo de ser e de se conduzir, que se completa em uma dimensão de ação, por meio das práticas de si. Essas práticas não são alguma coisa que o próprio sujeito invente, mas "esquemas que ele encontra em sua cultura, sua sociedade e seu grupo social” (FOUCAULT, 2004, p. 276); elas entram em conexão com a produção da vida como obra de arte e envolvem a criação de parcelas, ainda que pequenas, de mundos que se abrem em novas composições entre corpos. São outras sensibilidades, pensamentos e ações que implicam na imersão em um campo de experiências.

Os fragmentos apresentados a seguir, são expressão de alguns destes processos.

\section{Fragmento 1: leitura e escrita como prática estética e de cuidado de si}

Vivemos um cotidiano que nos incita ao medo e à passividade, e também à reprodução de valores que nos distanciam de nós, pensantes e persistentes na experiência e no cuidado de si (FOUCAULT, 2006). E o ambiente universitário, cada vez mais, incita à competição e ao individualismo, reproduzindo a lógica produtivista e corporativista que orienta nossos modos de pensar e agir na contemporaneidade, um tema já bastante problematizado.

As dificuldades para romper padrões na formação em saúde não são poucas porque estes estão cristalizados. Nesse sentido, ler, estudar, interpretar, descrever, narrar e escrever e posicionar-se diante das ideias dos autores são atividades que, apesar de presentes no cotidiano do trabalho intelectual, cada vez mais vem sendo desencorajadas ao longo do processo de formação, seja no âmbito da graduação ou da pós-graduação.

A formação técnica prevalece. A ênfase nas disciplinas e nas especialidades, em detrimento de uma aprendizagem inventiva dificulta a "constituição de uma base cultural para compreensão do significado do processo educativo enquanto parte integrante da dinâmica de socialização" (SILVA, 1992, p. 161).

O que pretendemos, em última instância, é transformar o espaço da sala de aula em espaço de experiência estética e de formação. A experiência é compreendida aqui "como uma expedição em que se pode escutar o "inaudito"” (LARROSA, 2010, p.10). A formação, por sua vez, é "um devir plural e criativo, sem padrão nem projeto, sem uma ideia prescritiva de seu itinerário e sem uma ideia normativa, autoritária e excludente de seu resultado" (LARROSA, 2010, p. 12).

Para a experimentação trabalhamos com as práticas de escrita, compreendidas como acontecimentos da pluralidade e da diferença, como aventuras rumo ao desconhecido, ou 
ainda como produções infinitas de sentido (KASTRUP, 2002) e que podem contribuir para esse pensamento aberto sobre formação (LARROSA, 2010).

Também aqui fica claro o uso do método da cartografia e do conceito de Aprendizagem Inventiva (KASTRUP, 2002) como referenciais teóricos e analíticos da experiência da escrita como prática estética, que pressupõe uma ética do saber implicado, assim como uma ética do cuidado de si.

Temos experimentado as práticas de escrita na sala de aula ${ }^{1}$ (ALVES; CARVALHO; DIAS, 2011), e os relatos dos estudantes dizem de uma descoberta e também de um contentamento. Poderíamos dizer que, em alguns, produz encantamento, diante das experiências surpreendentemente inusitadas no processo de formação. E, a partir delas, os estudantes nos chamam a atenção para a importância de conhecer outras perspectivas do processo ensino-aprendizagem no que diz respeito às experiências com o corpo, o livro e a escrita.

O espaço da sala de aula é o lugar onde problematizamos a experiência estética e investigamos as práticas como processos criativos transformadores de corpos e de relações (ALVES; CARVALHO, 2015). Nesse sentido, a figura da professora/tutora/orientadora do processo também se altera: ela oferece uma exigência, uma tensão, uma vontade, um desejo. A pesquisadora, por sua vez, provoca situações de desconforto e de deslocamento. Como escreveu Larrosa, procura elevar os estudantes "mais alto do que a si mesmos, ao que existe em cada um deles que é mais alto do que eles mesmos [...] puxa e eleva, faz com que cada um se volte para si mesmo e vá além de si mesmo, que cada um chegue a ser aquilo que é" (LARROSA, 2002, p. 12).

Larrosa (2010, p. 13) menciona as práticas de leitura, ele acredita que a virtude dela

[...] é sua infinita capacidade para a interrupção, para o desvio, para a 'desrealização' do real e do dado (inclusive do real e do dado de alguém) e para a abertura ao desconhecido. A iniciação à leitura aparece, assim, como o início de um movimento excêntrico, no qual o sujeito leitor abre-se à sua própria metamorfose.

Entendemos que essa qualidade da prática de leitura pode também ser uma qualidade da prática da escrita. Tal qual a "experiência da leitura como algo que põe o leitor em questão, tira-o de si e eventualmente o transforma" (LARROSA, 2010, p. 101), entendemos que a prática da escrita também pode provocar essa transformação (ALVES; CARVALHO; DIAS, 2011).

\footnotetext{
"O espaço da disciplina "Dimensões Filosóficas da Educação Física e do Esporte" na Escola de Educação Física e Esporte e o da disciplina "Saúde e Corpo" na Faculdade de Saúde Pública da Universidade de São Paulo tem sido usado para as práticas estéticas - de leitura e escrita - a partir do tema "Formação em Saúde" e, cada vez mais, fica evidente a importância e pertinência de insistirmos nessa qualidade de Experiência e com o aporte teórico da Aprendizagem Inventiva. Mas também a leitura e escrita em espaços de convivência e produção de trabalho e redes que se constituíram no campo da saúde, em projetos de integração ensino-serviço (CARVALHO, 2016).
}

São $60 \mathrm{~h}$ de carga horária na disciplina. A ideia é propor aos estudantes diferentes experimentações com as práticas corporais e estéticas, aqui especialmente as de escrita, explorando a mistura delas a fim de problematizar a respeito do "corpo em arte".

Dos procedimentos cabe mencionar que, inicialmente, agregam o acolhimento de todos, ou um modo de apresentar os participantes que instigue a atenção e o cuidado com o outro e consigo; depois, um aquecimento com exercícios de relaxamento e respiração para prepararmos o corpo para o "encontro" com a escrita; em seguida, definir um tema disparador para o trabalho da escrita - corpo e arte, por exemplo; explorar a prática propriamente dita, com exercícios de escrita (solta, sintética, objetiva, poética); observar sua escrita; olhar para e experimentar as escritas dos outros; narrar, escutar, conversar e trocar a respeito das diferentes experiências de escrita a fim de perceber o que cada um traz e instigar a troca de impressões a respeito do que foi realizado.

Trata-se de uma prática nos termos de uma "escrita de si” que não é uma prática descritiva do que aconteceu, mas uma prática que movimenta o pensamento (FOUCAULT, 2006). A formação aqui se transforma em uma prática estética, um campo de experimentação de si, como arte de viver (FOUCAULT, 2006, p. 146). Nesse campo, os exercícios de "escrita de si" produzem forças e funcionam como dispositivos capazes de acessar o inusitado, o intempestivo, o inenarrável do cuidado de si. E para perceber os fluxos que atravessam esta escrita, é preciso se deixar afetar, sem apego.

Como escrevemos em outro momento:

Não é fácil imprimir as intensidades da experiência no campo da escrita, mas, se lançar ao permanente aprendizado, em processos de formação abertos a experiência dessa qualidade da escrita, pode ser um caminho. Dobrar a atenção sobre as profundidades reveladas na "escrita de si" significa pensar a própria formação como um exercício de cultivo, que vai além de um período determinado, para se implicar na constituição da própria vida. E, isso também significaria a propagação indefinida da 'escrita de si' [e, em última instância, um cuidado de si] (ALVES; CARVALHO; DIAS, 2011, p. 255).

\section{Fragmento 2: corpo e experiência estética: aprendendo com mulheres da Noro ${ }^{2}$}

Os alunos estão acostumados a dormir na van, mas nesta experiência o corpo precisa estar desperto, de prontidão, para conhecer e encontrar os caminhos que levam a uma região de vulnerabilidade, para entrar em contato com os imprevistos que não são poucos: não sabem se a mulheres que vamos buscar em casa estão dispostas para o encontro, se há conflitos com a policia naquele momento, se a chuva provocou um transbordamento dos rios ou mesmo se obras que esburacam as ruas impedem o acesso às casas. ${ }^{3}$

${ }^{2}$ Projeto Delicadas coreografias iniciado em 2009, no módulo "Clínica integrada: produção de cuidado" com alunos dos diferentes cursos da saúde na Universidade Federal de São Paulo, Baixada Santista. Tem como objetivo geral a formação de uma clínica comum aos vários campos profissionais, avançando na produção e gestão do cuidado individual e coletivo em saúde.

${ }^{3}$ Arquivo pessoal. Esta narrativa foi retirada do "Caderno de registros" de uma das autoras, Flavia Liberman, também coordenadora do grupo de mulheres. Ali são 
Estes são alguns dos problemas que enfrentamos na realização de uma das nossas atividades de ensino. Tratase de ir a campo com estudantes para exercitar o cuidado. Nossa proposta é acompanhar um grupo mulheres com diferentes desafios por meio de práticas corporais e estéticas realizadas em um equipamento de arte e cultura da região.

Um trabalho artesanal. Aqui se aprende perseverança, paciência e atenção ao pequeno. Aqui se faz um trabalho corpo a corpo, tecido em micro movimentos. O corpo é afetado pelo encontro com a paisagem, pelos diversos cheiros, pelos becos, produzindo estados paradoxais: confortos e desconfortos, incômodos e satisfações, distanciamentos e aproximações (LIBERMAN; MAXIMINO, 2015). Deslocamentos da sala de aula para a rua, para outra realidade. Na maioria das vezes, os encontros "constituem oportunidades para saber mais de si, dos modos de funcionamento acessados na complexidade dos contatos" (LIBERMAN, 2008, p. 11), na tentativa de fugir dos mapas e trilhas habituais.

As mulheres com as quais trabalhamos vivem em condições socioeconômicas precárias, com difícil acesso a experiências que abordem o corpo em sua expressividade e possibilidade de comunicação com outros corpos o que, entre outros fatores, produz isolamento e diminuição do pulso vital (KELEMAN, 1992). Percebe-se também uma anestesia e neutralização da capacidade desejante.

Ampliar o acesso é um dos objetivos principais do nosso trabalho, porém não se trata somente do acesso concreto das pessoas em relação a sua mobilidade espacial, nem apenas disponibilizar ofertas. Trata-se de promover possibilidades para os encontros consigo, com as pessoas e com coisas. Acessibilidade é principalmente aquilo que pode possibilitar que algo aconteça.

Convidamos a todos os envolvidos, com delicadeza, a um investimento afetivo, corporal e vincular para mergulhar no desconhecido e se fazer mais presente para viver e produzir acontecimentos, inventando modos de criar, de se comunicar, pesquisar e construir corpos.

Keleman(1992) indica que os modos de funcionamento dos corpos são produzidos por vários fatores, entre outros, genéticos, culturais, hereditários, aos tipos de vínculo e experiências vividas ao longo da existência e aos atravessamentos da subjetividade dominante que modulam os comportamentos (FAVRE, 2012).

D. Zefa está com um xale amarelo, presente de uma aluna. Produz um novo corpo para este encontro. Nem sempre foi assim, nem há garantia de que seja nas próximas vezes. Há momentos em que é necessário tirá-la da cama, dar banho e vesti-la. Ela entra na van e fala: eu sou a mais nova aqui, sendo que ela é idosa e provavelmente nem sabe sua idade. Aquele corpo desdentado sorri quando diz: eu sou preta e você é minha filha branca, trazendo sua ancestralidade e a história, e lugar dos negros. Faz um gesto repetido de colocar as mãos no chão, com grande flexibilidade, para espanto de todos: foi o trabalho na enxada, diz, lá na minha terra. Estes gestos, também liberados pelas propostas realizadas, fazem surgir "as

registradas sensações, percepções e comentários sobre o trabalho desenvolvido. aparições”, os vários corpos que habitam D. Zefa. São os corpos que existem e os novos corpos que se tornam visíveis pelos dispositivos utilizados.

Esta narrativa singular de D. Zefa não se fecha nela mesma, reverberando no grupo, produzindo um contágio, "estes encontros podem funcionar como um dispositivo quando produzem um efeito de caráter ativo" (BARROS, 1996, p. 97) disparando algo em cada participante, dando ensejo a produções individuais e coletivas, ampliando a exploração dos territórios corporais.

Baremblitt (1992) nos diz que o dispositivo é um artifício de inovações que gera acontecimentos. Esta abordagem reafirma o caráter especialmente potente das práticas corporais e estéticas realizadas em grupo, que tentam resistir às imposições que anestesiam os corpos roubando seu caráter inventivo, distanciando-os uns dos outros, produzindo solidão e diminuição da potência de se presentificar no mundo.

No encontro do grupo de alunos e docentes com cada mulher busca-se instaurar um clima curioso e receptivo, exercitando um olhar que apreende o conjunto sem perder a singularidade nas propostas mais variadas: explorar objetos, lembrar de uma música, contar histórias, tocar outros corpos, brincar. Estas propostas são criadas a partir dos desejos e participação de todos e visam a exploração dos corpos, a ampliação da percepção e da sensibilidade, a instauração de um estado de presença.

Estar em grupo amplia a chance de acionar nos participantes o que Dewey (2010) chama de experiência estética, apostando que estas podem colocar a pessoa em movimento, desencadeando processos de criação, engendrando novos territórios existenciais, reinventando vidas (LIBERMAN, 2008). Os participantes são catalizadores e também testemunhas das experiências. Busca-se criar um território propício à surpresa, ao acolhimento do inesperado e ao acionamento de movimentos inventivos (KASTRUP, 2010).

No entanto, "A experiência estética não é aquela meramente divertida ou que gera entretenimento, mas sim aquela que é marcada por sensações intensas" (KASTRUP, 2010, p. 40), por vezes trazendo sofrimento: entrar na casa pequena de D. Nina e saber que seus três netos estão presos; aguentar o desconforto de não ter espaço para sentar e ao mesmo tempo escutar uma música que relativiza a importância do dinheiro; oferecer flores e sentir diferentes perfumes com uma mulher que está perdendo a visão.

A percepção sutil dos processos, o cuidado e o modo como se traz a proposta, a construção de um ambiente confiável e um respeito pelo tempo formativo favorecem que a experiência possa ser incorporada e atualizada para novas e outras situações.

O que mais ajuda a acessar a experiência estética? Cultivá-la. Deleuze diz que ele não acredita na cultura em si, mas nos encontros, não só com pessoas, mas, sobretudo com as coisas. Deleuze não procura os espaços de arte e produção cultural para ter mais cultura, mas para 
cultivar-se (DELEUZE, s.d., online). Portanto, cultivar pode ser compreendido como a abertura aos encontros, como um exercício de atenção à espreita.

No grupo fazemos um convite ao olhar-se, ao conhecer-se, ao reinventar-se. Experimentar o corpo significa tentar tocá-lo em suas mais diversas dimensões, entendendo-o como processos e espaço de passagem que procura dar formas às intensidades.

\section{Fragmento 3: criação e cuidado de si}

Em experimentações na arte contemporânea, acompanhamos o desenvolvimento de obras imanentes à vida e aos processos de criação de si e do mundo. Elas não se materializam em uma coisa ou objeto; possuem uma existência efêmera e se fazem presentes no mundo apenas no momento em que são experimentadas para depois se desfazerem, deixando atrás de si o rastro dos acontecimentos que se inscrevem na memória e restos materiais que permanecem no mundo.

Nessa perspectiva, a potência da obra, como processo formativo, revela-se na instauração de campos de dizibilidades e visibilidades inusitados, e na abertura de possibilidades para a sensibilidade, o pensamento e a aprendizagem. 325)

Como nos ensina Favaretto (apud LIMA, 2006, p.

Na busca de novos rumos da sensibilidade contemporânea [...], a atividade artística desloca o acento das obras para a produção de acontecimentos, ações, experiências, objetos [...], liberando uma significação básica: a reinvenção da arte é condição para que ela possa intervir na transformação radical do homem e do mundo. Assim fazendo, estaria realizando e ultrapassando as categorias de arte, tornadas categorias de vida.

A obra de Sophie Calle, Cuide de você, que esteve em exposição em São Paulo no Sesc Pompéia, é uma experimentação desse tipo e coloca em foco as relações entre o cuidado e a criação artística. $\mathrm{O}$ trabalho foi desenvolvido a partir de uma mensagem de e-mail recebida pela artista, na qual seu namorado rompia o relacionamento que havia entre eles. A mensagem terminava com um usual "cuide de você" - take care of yourself ou, na língua da artista, prenez-soin de vous -, como um "até mais" ou "nos vemos por aí".

Recebi um email de rompimento. E não soube respondê-lo. Era como se ele não me fosse destinado. E terminava com as palavras: Cuide de você. Levei essa recomendação ao pé da letra. Pedi a 107 mulheres, escolhidas por sua profissão, para interpretar a mensagem por um ângulo profissional. Analisá-la, comentá-la, cantá-la, dançar com ela. Dissecar a mensagem. Esgotá-la. Compreender por mim. Responder no meu lugar. Uma maneira de ganhar tempo para romper. No meu ritmo. Cuidar de mim (CALLE, 2008, tradução nossa).

A dor provocada pela mensagem pede um desdobramento; o acontecimento não para aí. Mas como fazê-lo passar? (ROLNIK, 2015). Sophie Calle é uma artista singular na cena contemporânea, que sabe manejar de uma forma particular os tênues liames da vida singular e coletiva. Ela usará sua maestria de transitar pelas esferas da subjetividade e da cultura para tratar sua própria dor. Sua forma de se cuidar é desenvolver o problema que o acontecimento envolve, efetuá-lo, fazê-lo terminar de acontecer.

Produzindo a vida como obra de arte, Sophie começa a cuidar de si pluralizando-se; ela é muitas, torna-se muitas. Para tratar de si pede a diferentes mulheres que interajam com a mensagem a partir de suas profissões, em um jogo de espelhos que multiplica infinitamente o que faz a própria artista a partir de seu metier, que é o da arte conceitual.

São mulheres que, como ela, perderam um amor. A carta irá reativar em cada uma a dor, criando novas respostas, que se multiplicam: pode-se atirar na carta, num gesto de precisão e violência, que quase nos provoca uma espécie de alívio; pode-se desabar sobre ela; podese interpretá-la, corrigi-la, traduzi-la para outras línguas, transportá-la para outros contextos; pode-se dançar com ela ou fazê-la desaparecer como num passe de mágica.

Tantos são os caminhos possíveis para a travessia da dor do fim do amor...

E o que esta obra produz no público? Que dores ressuscita ou reativa? Que caminhos tortuosos se trilha para atravessar a perda, o fim do amor? As pessoas que visitam a exposição provavelmente conhecem esses caminhos, algumas já os trilharam em sua vocação solitária. Cada um é a $108^{\mathrm{a}}$ mulher a quem Sophie pede que responda a carta.

\section{Este fragmento de texto é a minha resposta.}

A resposta de Sophie é a produção de respostas em cascata. Sophie multiplica-se em muitas mulheres e faz proliferar os modos possíveis para si, mas também para nós. Do desprezo e deboche, ao ódio e ao dilaceramento, as emoções ganham contorno e forma nas produções que não são nunca somente uma resposta à carta, mas sim um envolvimento com ela que desenvolve o acontecimento que ela produziu.

Como médica de si e do mundo (DELEUZE, 1997), Sophie se cuida, se trata e trata também de nós, o público. O problema aqui não é mais somente de Sophie e seu namorado. Aqui, trata-se do amor nos tempos da internet, das viagens, das distâncias, dos espaços entre corpos. Nos tempos de aproximações e evitações, da busca de intimidade com muito pouco contato, da falta de olhar nos olhos e tocar a pele.

Ao cuidar de si, a artista, descobre um coletivo, uma dor que se desindividualiza, uma alegria de não estar só. E nós descobrimos a alegria do depois do amor, do além da dor, que é a alegria da criação de si, depois que tudo desmoronou, e da criação de uma parcela pequena de mundo. Um novo mundo que se abre para que inventemos outras formas de vida possíveis.

Visitar exposições como esta faz parte da formação dos estudantes de Terapia Ocupacional da USP: a exploração de diferentes campos das atividades humanas tem a potência de interferir nos processos de subjetivação, 
atuando na produção de saberes, na construção de corpos e gestos, na experimentação de formas de estar no mundo, de cuidar e de criar.

$\mathrm{Na}$ disciplina Atividades e Recursos Terapêuticos: Processos Criativos, ${ }^{4}$ vamos juntos com os estudantes a exposições que estão em cartaz na cidade, na busca de que esse deslocamento da sala de aula em direção ao mundo e aos territórios culturais possa provocar estranhamento e afeta-los de tal forma que processos de pensamento e criação sejam desencadeados.

Nossa propostaéinstaurarum campo de experimentação que convoque nos corpos um estado de presença para que encontros, trocas e produção de conhecimento compartilhado possam ocorrer. Esta proposta se aproxima fortemente do campo das artes, com vivências em ateliê, pesquisa em arte, propostas de apreciação em sala de aula e em espaços expositivos e desenvolvimento de trabalhos poéticos em diálogo com práticas artísticas contemporâneas que têm deslocado o foco dos objetos para os acontecimentos, que tocam as práticas grupais e que dialogam com experiências de aprendizagem.

A arte, por suas características de invenção e de integração do processo ao produto, favorece as experiências estéticas. É fruição, aproveitamento e consumação em si mesma: "A experiência, na medida em que é experiência, consiste na acentuação da vitalidade, uma troca ativa e alerta com o mundo; que em seu auge significa uma interpenetração completa entre o eu e o mundo, os objetos e acontecimentos" (DEWEY, 2010, p. 83).

A atividade artística está associada também à criação de desejo. Se a arte é a realização de um desejo tratase de um desejo intensificado pelo próprio ato artístico e não dado por antecipação. Em oposição aos processos mecânicos, a arte desenrola-se de maneira inusitada e "o suspense, na arte, é um apetite que aumenta a partir daquilo com que é alimentado" (KAPLAN apud DEWEY, 2010, p. 28).

No contexto da disciplina, as visitas a exposições de arte e o contato com obras que encarnam, envolvem e desenvolvem um campo problemático, visam favorecer a experiência estética, a intensificação de desejo e a ativação da sensibilidade. Aprendizagem é entendida aqui como um processo movido por desejo, interesses e capacidades, que provoca transformações e cria novas formas de ser, articulando a possibilidade de compartilhar conhecimentos e saberes e de construir caminhos próprios e singulares na pluralidade da existência humana.

O contato com as obras também permite o encontro com mapas de sentido que funcionam como guias para que se possa enfrentar as desestabilizações subjetivas que participam dos processos de criação e dos processos de cuidado. Para Suely Rolnik (1997), relações de força inéditas atravessam os corpos e ganham forma, sentido e valor em microuniversos culturais e artísticos através de cartográficas musicais, visuais, cinematográficas,

\footnotetext{
${ }^{4}$ A disciplina "Atividades e Recursos Terapêuticos: Processos Criativos" - do Curso de Terapia Ocupacional da Universidade de São Paulo - compõe a formação no campo das práticas artísticas, corporais e culturais que são desenvolvidas pelo Laboratório de Estudos e Pesquisa Arte e Corpo em Terapia Ocupacional.
}

teatrais, arquitetônicas, literárias, filosóficas, etc. "Tais cartografias ficam à disposição do coletivo afetado por este ambiente, como guias que ajudam a circular por suas desconhecidas paisagens" (ROLNIK, 1997, p. 3).

A partir da imersão em múltiplas experiências, do contato com obras de arte e da produção de um caderno de criação - no qual são exploradas diferentes formas de registro de processo -, os terapeutas ocupacionais em formação são acompanhados na elaboração de um projeto poético que possibilite decifrar os signos que se fizeram enigma em seu corpo. A imersão em processos de criação estimula os estudantes a construírem suas próprias cartografias sensíveis que expressem a viagem realizada e, ao mesmo tempo, funcionem como suporte para o trabalho com as múltiplas questões disparadas. Busca-se assim, inserir na formação de terapeutas, o exercício das práticas de si, numa implicação ética com a constituição de si mesmo como alguém que se prepara para cuidar dos outros. Como nos ensina Foucault (2004, p. 271), o cuidado de si é ético e "implica relações complexas com os outros, uma vez que esse êthos da liberdade é também uma maneira de cuidar dos outros".

\section{Tecendo relações e algumas considerações finais}

No relato de algumas das experiências com práticas corporais e artísticas é possível perceber a miríade de problematizações que emergem do vivido. Questões que deslocam saberes pré-estabelecidos e, por meio de fragmentos, buscam dar visibilidade a territórios habitados por aquilo que é quase imperceptível e que se expressam na dimensão dos gestos, das sensorialidades, das linguagens, do pensamento. Não é tudo que se transforma em experiência, que se incorpora como repertório e que poderá ser acessado em outras situações. Algumas vivências, embebidas de afetos e sentidos, produzem marcas nos corpos, pedem decifração e impulsionam processos de criação. Aqui a arte é um direito e, portanto, acessível a qualquer um; modifica ambientes; possibilita maior conexão consigo e com o entorno na produção de realidades que alargam sensibilidades, constituindo corpos porosos às afetações do mundo que nos atravessam permanentemente.

Em nossos fragmentos observamos, por vezes, esgotamento, colapso, enrijecimento e anestesia dos corpos. Neste sentido, qualquer ação que se queira transformadora deverá compreender um trabalho com o corpo e com a sensibilidade. Debruçar-se sobre as experiências, tanto na vertente formativa, quanto nas interferências em campo, revela-nos que é possível produzir sensibilidades mais atentas ao que é vivo e ao pulso vital, e modificar, mesmo que de modo sutil, as relações e os modos de cuidar.

Finalizando, práticas corporais artísticas, experiências estéticas, Aprendizagem Inventiva e cuidado de si são empreendimentos de saúde e o leitor, o escritor e o artista, como médico de si e do mundo, põe em jogo a invenção de novas línguas para acontecimentos que se dão na fronteira da linguagem.

Fractal, Rev. Psicol., v. 29 - n. 2, p. 118-126, 2017 
E aqui nos lembramos dos fractais...

Formas geométricas com padrões complexos que se repetem infinitamente...

Estão em todos os corpos: vegetais, animais, minerais...

Estão nos nossos corpos...

Dos equipamentos mais sofisticados, como as próteses, até os corpos em arte...

O princípio dos fractais inspira a produção de música, literatura e movimento

Nos corpos produzindo escuta, conversa, toques, sons, músicas, ritmos, gestos... aprendizagem e cuidado.

\section{Referências}

ALVES, F. S.; CARVALHO, Y. M. A Educação Física no plano da experiência: implicações na pesquisa e na intervenção profissional e docente. Pensar a Prática, Goiânia, v. 18, n. 1, p. 223-233, jan./mar. 2015. Cross ${ }^{\text {Ref. }}$

ALVES, F. S.; CARVALHO, Y. M.; DIAS, R. A "escrita de si" na formação em Educação Física. Movimento: Revista de Educação Física da UFRGS, Porto Alegre, v. 17, n. 2, p. $239-$ 258, 2011. Disponível em: <http://www.seer.ufrgs.br/index. php/Movimento/article/view/20214/13140>. Acesso em: 22 out. 2016

BAREMBLITT, G. F. Compendio de Análise Institucional e outras correntes: teoria e prática. Rio de Janeiro: Rosa dos Ventos, 1992.

BARROS, R. D. B. Dispositivos em ação. Cadernos de subjetividade [Dossiê: Gilles Deleuze], São Paulo, v. 4, n. 1, p. 97-106, 1996.

CALlE, S. Prenez soin de vous. Exposition mise en scène par Daniel Buren. Bibliothèque nationale de France, 2008. Disponível em: <http://www.bnf.fr/documents/dp_calle.pdf>. Acesso em :10 nov. 2016.

CARVALHO, Y. M. Apresentação. In: JUNQUEIRA, S. R.; CARVALHO, Y. M. Formação em saúde: experiências nos serviços e inovações coletivas. São Paulo: Yendis, 2016. p. 9-10.

DELEUZE, G. O Abecedário de Gilles Deleuze, A de animal. Transcrição integral do vídeo. Disponível em: $<$ http://stoa.usp. br/prodsubjeduc/files/262/1015/Abecedario + G. + Deleuze.pdf $>$. Acesso em :10 nov. 2016.

DELEUZE, G. Crítica e Clínica. São Paulo: Editora 34, 1997.

DELEUZE, G. Michel Foucault. In: Rio de Janeiro: Editora 34, 2000. p. 103-147.

DELEUZE, G. Diferença e repetição. Rio de Janeiro: Graal, 1988.

DEWEY, J. A arte como experiência. São Paulo: Martins Fontes, 2010.

FAVRE, R. Presença. Laboratório do Processo Formativo, 2012. Disponível em: <http://www.laboratoriodoprocessoformativo. com>. Acesso em: 10 nov. 2016.

FOUCAULT, M. História da Sexualidade: o cuidado de si. Rio de Janeiro: Graal, 1985. v. 3.

Fractal, Rev. Psicol., v. 29 - n. 2, p. 118-126, 2017
FOUCAULT, M. A ética do cuidado de si como prática de liberdade. In: MOTTA, M. B. da (Org.). Ética, Sexualidade e Política. Rio de Janeiro: Forense Universitária, 2004. Coleção Ditos \& Escritos, v. 5, p. 264-287.

FOUCAULT, M. A hermenêutica do sujeito. São Paulo: Martins Fontes, 2006.

GUATTARI, F.; ROLNIK, S. Micropolítica: cartografia do desejo. Petrópolis, RJ: Vozes, 1986.

KASTRUP, V. Aprendizagem, arte e invenção. Psicologia em Estudo, Maringá, v. 6, n. 1, p. 17-27, jan./jun. 2001. Cross ${ }^{\text {Ref. }}$

KASTRUP, V. Cartografias Literárias. Revista do Departamento de Psicologia - UFF, Niterói, v. 14, n. 2, p. 23-38, 2002.

KASTRUP, V. A aprendizagem da atenção na cognição inventiva. Psicologia \& Sociedade, Porto Alegre, v. 16, n. 3, p. 7-16, set./dez. 2004. Cross ${ }^{\text {Ref. }}$

KASTRUP, V. O devir-consciente em rodas de poesia, Revista do Departamento de Psicologia - UFF, Niterói, v. 17, n. 2, p. 45-60, jul./dez. 2005.

KASTRUP, V. O Funcionamento da atenção no trabalho do cartógrafo. Psicologia \& Sociedade, Porto Alegre, v. 19, n. 1, p. 15-22, jan./abr. 2007. Cross ${ }^{\text {Ref. }}$

KASTRUP, V. Experiência estética para uma Aprendizagem Inventiva: notas sobre acessibilidade de pessoas cegas a museus. Informática na educação: teoria e pratica, Porto Alegre, v. 13, n. 2, p. 38-45, jul./dez, 2010.

KELEMAN, S. Anatomia emocional. São Paulo: Summus, 1992.

LARROSA, J. L. Notas sobre a experiência e o saber de experiência. Revista Brasileira de Educação, Rio de Janeiro, n. 19, p. 20-28, jan./abr. 2002. Cross ${ }^{\text {Ref. }}$

LARROSA, J. Pedagogia profana: danças, piruetas e mascaradas. Belo Horizonte: Autentica, 2010.

LIBERMAN, F. Delicadas coreografias: instantâneos de uma terapia ocupacional. São Paulo: Summus, 2008.

LIBERMAN, F.; MAXIMINO, V. (Org.). Planos grupais e experiência estética: friccionando ideias, emoções e conceitos. In: _. Grupos e Terapia Ocupacional, formação, pesquisas e ações. São Paulo: Summus, 2015. p. 115-127.

LIMA, E. M. F. A. Por uma arte menor: ressonâncias entre arte, clínica e loucura na contemporaneidade. Interface (Botucatu), Botucatu, v. 10, n. 20, p. 317-329, jul./dez. 2006. Cross ${ }^{\text {Ref. }}$

PASCUAL, J. G., JUSTA, R. A Aprendizagem Inventiva no ensino de psicologia. Arq. bras. psicol., Rio de Janeiro, v. 61, n. 3, p. 23-34, dez. 2009. Disponível em: <http://pepsic. bvsalud.org/scielo.php? script=sci_arttext\&pid=S1809$52672009000300004 \& \operatorname{lng}=$ pt\&nrm $=$ iso $>$. Acesso em: 22 out. 2016.

PASSOS, E.; KASTRUP, V.; ESCOSSIA, L. (Org.). Pistas do método da cartografia: pesquisa-intervenção e produção de subjetividade. Porto Alegre: Sulina, 2010.

ROLNIK, S. Pensamento, corpo e devir: uma perspectiva ético/ estético/ política no trabalho acadêmico. Cadernos de Subjetividade, São Paulo, v. 1, n. 2, p. 241-251, 1993.

ROLNIK, S. Uma insólita viagem à subjetividade: fronteiras com a ética e a cultura. 1997. Disponível em: $<$ http://www. pucsp.br/nucleodesubjetividade/suely\%20rolnik.htm>. Acesso em: 10 nov. 2016. 
ROLNIK, S. Una conversación con Suely Rolnik (Universidad católica de Sao Paulo). [2015]. Re-visiones, Madrid, n. 5, 2015. Entrevista concedida a Aurora Fernández Polanco e Antonio Pradel. Disponível em: <http://www.re-visiones.net/spip. php\%3Farticle128.html>. Acesso em:10 nov. 2016.

SANCOVSCHI, B.; KASTRUP, V. Práticas de estudo contemporâneas e a aprendizagem da atenção. Psicologia \& Sociedade, Belo Horizonte, v. 25, n. 1, p. 193-202, 2013. Cross ${ }^{\text {Ref. }}$

SILVA, F. L. Por que filosofia no segundo grau. Estudos Avançados. São Paulo, v. 6, n. 14, p. 157-166, jan./abr. 1992. Cross ${ }^{\text {Ref. }}$

SPINOZA, B. Ética. Belo Horizonte: Autêntica, 2007.

Recebido em: 14 de novembro de 2016 Aceito em: 18 de julho de 2017 